\title{
PEDAGOGIA HISTÓRICO-CRÍTICA E AVALIAÇÃO EXTERNA: NOTAS PARA A ELABORAÇÃO DE UMA AVALIAÇÃO EMANCIPADORA
}

\author{
Dra. Hellen Jaqueline Marques 0000-0003-1146-2801 \\ Dr. Fabiano Antonio Santos 0000-0002-7703-8520 \\ Universidade Federal de Mato Grosso do Sul
}

\begin{abstract}
RESUMO: A escola é, na perspectiva da pedagogia histórico-crítica, o local de excelência para a transmissão dos conhecimentos científicos, artísticos e filosóficos, na direção de uma formação humana omnilateral. Esta afirmação torna-se fundamental quando analisamos as avaliações externas na educação escolar e a crescente tendência da lógica gerencialista e de conteúdos voltados às exigências do mercado de trabalho capitalista, além da consideração apenas de fatores intraescolares como definidores da qualidade da educação. Este artigo objetiva problematizar a lógica de avaliação externa hegemônica no contexto
\end{abstract}

brasileiro e elaborar princípios para uma avaliação emancipadora. Não com o objetivo de responsabilizar e ranquear escolas, mas oferecer um diagnóstico sobre a realidade escolar, suas fragilidades e potencialidades, e, principalmente, identificar as relações entre o desenvolvimento da sociedade e a individualidade dos indivíduos. Tal perspectiva tem o intuito de possibilitar a reflexão e construção de formas de acompanhamento do ensino e da aprendizagem, considerando o enriquecimento da formação do gênero humano e seu potencial de transformação social.

PALAVRAS-CHAVE: Pedagogia Histórico-crítica; avaliação externa; avaliação emancipadora.

\section{HISTORICAL-CRITICAL PEDAGOGY AND EXTERNAL EVALUATION: NOTES FOR THE ELABORATION OF AN EMANCIPATING EVALUATION}

\begin{abstract}
The school is, from the perspective of historical-critical pedagogy, the place of excellence for the transmission of scientific, artistic and philosophical knowledge, in the direction of an omnilateral human formation. This statement becomes essential when we analyze external evaluations in school education and the growing trend of managerialist logic and of contents turned to the demands of the capitalist labor market, besides the considering only intra-school factors as defining the quality of education. This article aims to problematize the hegemonic external evaluation logic in the
\end{abstract}

Brazilian context and to elaborate principles for an emancipatory evaluation. Not with the objective of to hold responsible and to rank schools, but to offer a diagnosis about the school reality, its weaknesses and potentialities, and, mainly, identify the relationships between the development of society and the individuality of individuals. This perspective is intended to enable reflection and construction of ways of monitoring teaching and learning, considering the enrichment of the training of humankind and its potential for social transformation.

KEYWORDS: Historical-Critical Pedagogy, External Evaluation, Emancipatory Evaluation. 


\section{Educere "Educare \\ RevisTa de Educacĩo \\ Programa de Pós-Graduação em Educação - Universidade Estadual do Oeste do Paraná}

\section{INTRODUÇÃO}

O Brasil, em decorrência da produção de uma agenda globalmente estruturada para a educação (DALE, 2004), tem adotado uma série de políticas que visam inserir uma lógica gerencial de gestão das escolas e, com isso, assumir uma perspectiva mercadológica e privatista. Ainda que a educação pública não deixe de existir, sua gestão vai se modificando e tomando os contornos privados de gestão e organização do trabalho pedagógico.

No bojo dessa agenda internacional, o país tem buscado figurar com destaque dentre os países periféricos e isso pode ser percebido a partir de uma análise rápida das principais ações desenvolvidas pelos governos brasileiros nos últimos 30 anos. Desde o Lançamento do Plano Decenal de Educação Para Todos, em 1993, passando pela aprovação da LDB de 1996, e incluindo os mais recentes como o Plano de Desenvolvimento da Educação (2007) e a Base Nacional Comum Curricular (2018) o que se pode identificar é a vinculação, cada vez maior, entre as políticas desenvolvidas pelo estado brasileiro com aquelas propostas pelos Organismos Multilaterais, que vão se tornando importantes influenciadores nas decisões políticas do setor educacional de países como o Brasil.

De acordo com Melo e Aragão (2017), essas interferências sobre a educação promovidas pelos Organismos Multilaterais têm como eixo central, dentre outras ações, a avaliação em larga escala. Para os autores, as políticas de avaliação externa ganham espaço no cenário brasileiro a partir dos anos 1990 tendo como inspiração os princípios neoliberais. Segundo Bauer, Alavarse e Portela (2015) a avaliação externa caracteriza-se por um conjunto de medidas que se articulam em torno de quatro aspectos: a centralização dos sistemas de avaliação que passam a se comportar como verdadeiros instrumentos de gestão, disseminando valores considerados desejáveis; a descentralização da gestão e do financiamento, que objetiva incutir o discurso da autonomia (financeira) das 


\section{Educere Educare \\ ReVISTA DE EduCACÃo}

Programa de Pós-Graduação em Educação - Universidade Estadual do Oeste do Paraná

escolas e da gestão compartilhada (diferentemente da gestão democrática, os princípios da gestão compartilhada são os mesmos de uma empresa); a ampliação das possibilidades de escolha dos alunos pelas escolas melhores ranqueadas; valorização dos resultados em nome de uma suposta maior efetividade nos serviços oferecidos.

Diante deste cenário, este artigo tem como objetivo problematizar a lógica de avaliação externa hegemônica no contexto brasileiro e, em contrapartida, apontar princípios para uma avaliação emancipadora, pautada na pedagogia histórico-crítica.

Desde uma perspectiva que defendia a educação para todos, com a conferência de Jontiem, até a concretização de uma "educação para poucos" (MÉLO; ARAGÃO, 2017), o percurso da avaliação tem sido atrelado às propostas meritocráticas, com objetivo de avaliar não o processo, muito menos apresentar soluções aos problemas, mas mensurar e diferenciar os alunos "bons" daqueles considerados insuficientes. O sucesso destes alunos dependeria da qualidade dos professores o que, portanto, estrutura uma lógica de responsabilização dos docentes pela qualidade da educação. Todo esse mecanismo é incorporado na avaliação de larga escala que teria o objetivo de mensurar a qualidade do ensino e, consequentemente, dos seus professores.

O que pretendemos apresentar e discutir é que essa lógica hegemônica de avaliação em larga escala não atende aos interesses da educação numa concepção emancipadora. Não é possível negar a importância das avaliações em larga escala quando estas atuam como diagnóstico e não apresentam impactos negativos sobre o funcionamento das escolas. É com esse intuito que apresentamos a pedagogia histórico-crítica como concepção capaz de orientar a avaliação em larga escala sob outros objetivos e princípios, mais voltados aos interesses da classe trabalhadora e, principalmente, focados no desenvolvimento integral dos alunos, no sentido da formação do gênero humano. 


\title{
Educere Educare \\ ReVISTA DE EduCACÃ̃o
}

Programa de Pós-Graduação em Educação - Universidade Estadual do Oeste do Paraná

\section{TRAJETÓRIA DA AVALIAÇÃO EXTERNA NO BRASIL: CONSEQUÊNCIAS PARA A EDUCAÇÃO ESCOLAR}

A avaliação externa no Brasil tem sido marcada pela busca de padrões internacionais de proficiência, considerados adequados para escolas que visam oferecer um ensino "de qualidade". Essa afirmação deve ser compreendida em associação com a função e implicações que, historicamente, a avaliação tem apresentado não somente em nosso país, mas em todo o mundo. Nos Estados Unidos, por exemplo, ganhou tamanha importância que a vida das pessoas foi alterada. Especulação imobiliária na região onde estão as escolas melhores avaliadas, famílias que migram para essas regiões para garantir vagas a seus filhos, estados e municipios que se baseiam nos resultados das avaliações para definir prioridades nas políticas educacionais são amostras do que enfrenta o país norte-americano.

\begin{abstract}
Nas últimas décadas, os resultados dos testes dominaram o discurso sobre escolas e suas ações. As famílias agora tomam decisões importantes, como onde morar, com base nas pontuações desses testes. Isso ocorre porque os agentes imobiliários usam as pontuações dos testes obtidos pelas escolas para avaliar a qualidade da vizinhança, afetando os valores das propriedades. Testes têm demonstrado que as pontuações afetam os preços das habitações, resultando em uma diferença de US \$ 9.000 entre casas localizadas nos bairros da classe "A" ou "B". Nos níveis nacional e estadual, os resultados dos testes agora são comumente usados para avaliar programas e alocar recursos educacionais (AMREIN; BERLINER, 2002, p. 03, tradução nossa).
\end{abstract}

Assim como nos Estados Unidos, a principal potência econômica no mundo capitalista contemporâneo, em outros países a política de avaliação externa ganhou importância e passou a definir uma série de políticas educacionais relacionadas: política de formação de professores, políticas de melhoria da qualidade, políticas de implementação de gestão nas escolas foram se moldando àquilo que exigia as políticas de avaliação.

Amrein e Berliner (2002) continuam a analise sobre as politicas de avaliação apontando alguns argumentos que se tornaram comuns entre aqueles que defendem as politicas de avaliação externa. Segundo os autores, o primeiro 


\section{Educere Educare \\ ReVISTA DE EduCACÃ̃o}

Programa de Pós-Graduação em Educação - Universidade Estadual do Oeste do Paraná

argumento frequente defende os testes de altas consequências como ferramenta para que professores e alunos saibam o que é importante ensinar e aprender. O segundo argumento que destacam é que os professores precisariam ser responsabilizados através destes testes porque essa seria uma forma de motiválos a ensinar melhor, em especial àqueles mais "preguiçosos". Um terceiro argumento indica que os estudantes trabalhariam mais duro e aprenderiam mais quando fossem submetidos aos testes de alto impacto. Outro argumento defende que os alunos seriam motivados a dar o melhor de si se submetidos à pressão dos testes. Por fim, argumenta-se que o sucesso nos testes levaria os alunos a ter sentimento positivo ao passo que, se os resultados fossem ruins, isso os motivaria a querer melhorar até alcançar os padrões estabelecidos. O que os autores apontam é um panorama importante de argumentos usados não somente dentre os defensores da política de avaliação estadunidense, eles apresentam argumentos que se cristalizaram em todo o mundo, e que usados com frequência vão se tornando verdades quase inquestionáveis.

É neste contexto de grande aceitação destas avaliações que o Brasil vem se empenhando em aproximar sua estratégia de aplicação dos testes às estratégias de países centrais (com exceção do Chile que, mesmo sendo país periférico, é tomado como exemplo de implementação de políticas avaliativas com consequências para a escola).

A avaliação da aprendizagem no Brasil remonta o período da colonização portuguesa, quando da chegada dos Jesuitas. Ainda que o foco deste artigo não seja a avaliação interna da aprendizagem, vale mencionar os primeiros passos da avaliação no país uma vez que este movimento foi responsável por orientar as estratégias e instrumentos de avaliação do país posteriormente. A avaliação, como sinônimo de provas e exames, é uma herança datada de 1599 (BARONI; BONFIM, 2017), mas é a partir da chegada da coroa portuguesa ao país, durante o século XIX, que ocorre grande desenvolvimento da educação e, com isso, a criação de cursos de ensino superior e de colégios particulares. Essas mudanças passam a exigir novos instrumentos avaliativos, agora voltados a mensurar a 


\section{Educere "Educare \\ ReVISTA DE EduCAČ̃̃o}

Programa de Pós-Graduação em Educação - Universidade Estadual do Oeste do Paraná

aprendizagem destes novos alunos que ingressavam no recém-criado ensino superior.

Ainda que este período seja importante por marcar mudanças importantes no sistema educacional brasileiro é com o advento da república que a autonomia e soberania conferem significativas alterações tanto na concepção da avaliação como na sua execução.

Segundo Baroni e Bonfim (2017) as avaliações realizadas no período que vai até a década de 1920 se constituía num processo individualizado e composto, normalmente, por uma junta examinadora que solicitava ao estudante escrever ou citar um teorema ou um conceito, mesmo que essa atividade não estivesse relacionada ao contexto vivido pelo estudante. Entretanto, esse processo mais individualizado se mostrou lento na medida em que os sistemas de ensino cresciam e o número de alunos para avaliar se tornava maior. Essa nova condição levou a adoção de outro mecanismo de avaliação: os testes para ingressar no sistema de ensino. Inclusive, este novo sistema de avaliação se tornou hegemônico e, com ele, o aumento do uso da avaliação como forma de passagem para níveis de ensino superiores (no caso a passagem para o colegial, etapa da educação brasileira que se tornava cada vez mais procurada a partir dos anos 30 do século passado). Esse primeiro momento da avaliação no país, que vai até os anos 1960, passa a ter um caráter classificatório mediante resultados alcançados pelos estudantes em exames e provas (BARONI; BONFIM, 2017).

É com a aprovação da LDB de 1961 que o olhar e, consequentemente, a função da avaliação vai se transformando. A partir da promulgação da lei, o processo avaliativo passa a ser responsabilidade das escolas. Isso altera, também, o papel do professor que antes era responsável pela transmissão dos conhecimentos, deixando à cargo do governo central a avaliação, passando para ele mesmo o papel de avaliar a aprendizagem dos alunos. A ampliação do escopo da avaliação trouxe consigo novas indagações sobre o ato de avaliar em si (e até para si). Ou seja, iniciam-se reflexões sobre o ato de avaliar em si suas 


\section{Educere Educare \\ ReVISTA DE EduCACÃ̃o}

Programa de Pós-Graduação em Educação - Universidade Estadual do Oeste do Paraná

concepções, finalidades e utilizações para fins que não apenas mensurar a aprendizagem. Também passa a ser discutida a avaliação sob o ponto de vista para si, ou seja, que utilidades a avaliação da aprendizagem teria como instrumento normativo de controle, por exemplo.

Uma década depois, nos anos 1970, a nova LDB oferece compreensão da avaliação de um ponto de vista mais qualitativo. Nesta dimensão, o importante estaria menos no resultado final e mais no processo, pois é ele quem determinava o sucesso ou fracasso do resultado final da avaliação. Nesta nova perspectiva, não importava o resultado final, se não viesse acompanhado de processos qualitativos capazes de gerar aprendizagens significativas e desenvolvimento no aluno.

Avançando para os anos 1990, a promulgação da LDB em 1996 marca novos avanços sobre a legislação que trata a avaliação. Agora termos como avaliação contínua e cumulativa, avaliação numa perspectiva muldimensional, incorporando possibilidades de avaliar o processo de forma mais ampla e garantindo possibilidade de avaliar com vistas a acelerar estudos, recuperar conteúdos perdidos em paralelo aos conteúdos regulares, etc.

Esse contexto histórico da avaliação da aprendizagem realizada no Brasil nos dá a dimensão de sua importância para o próprio desenvolvimento da educação. Como acompanharemos, a política de avaliação adotada no país se torna tão importante que muitas outras políticas vão se originar a partir da concepção adotada pelas primeiras. A política de formação de professores, de melhoria da qualidade são exemplos emblemáticos da influência que a política de avaliação externa tem sob o país.

As primeiras experiências com aplicação de avaliações externas no país datam dos anos 1960 e tem seu emprego associado, naquele momento, aos vestibulares que cresciam no país (GATTI, 1987). Como acompanhamos anteriormente, o crescimento dos sistemas educacionais não comportava mais avaliações individualizadas, levando a adoção de testes mais gerais que, por sua 


\section{Educere Educare \\ ReVISTA DE EduCAČ̃̃o}

Programa de Pós-Graduação em Educação - Universidade Estadual do Oeste do Paraná

vez, impulsionou testes para ingresso em níveis superiores de ensino (como foi o caso de acesso ao colegial).

De acordo com Gatti (2013), foi a partir dos anos 1960 que as avaliações de rendimento da aprendizagem, realizadas em maior escala se constitui no país.

Foi nessa década que surgiu fortemente a preocupação específica com processos avaliativos escolares, baseados em critérios mais claramente enunciados e instrumentos que poderiam garantir, até certo ponto, que a avaliação do nível de realização obtido estivesse mais objetivamente garantida. Essa foi a década em que a preocupação com a operacionalização dos objetivos de ensino e as técnicas de ensino ganhou fôlego (GATTI, 2013, p. 50).

A autora prossegue destacando a década seguinte (1970) e um importante estudo realizado em nível Latinoamericano a partir da iniciativa do Programa de Estudos Conjuntos de Integração Econômica Latino-americana (ECIEL). Segundo Gatti (2013) esse estudo avaliativo foi importante pois envolveu não apenas testes cognitivos, mas dados econômicos, sociais que ampliariam a compreensão da funcionalidade das avaliações externas.

Como participante de uma equipe responsável por traçar linhas gerais de uma avaliação externa e de larga escala para escolas brasileiras, Gatti (2013) relata que sua equipe, pertencente à Fundação Carlos Chagas, fora procurada pelo Ministério da Educação em 1987 para elaborar uma prova que pudesse apresentar dados mais concretos sobre a aprendizagem dos alunos brasileiros. Influenciado por uma visita feita aos Estados Unidos, o então ministro da Educação Aluísio Sotero ficou bastante impressionado com a descentralização das políticas educacionais daquele país e, ao mesmo tempo, a centralização das avaliações que, naquele momento no Brasil ficava a cargo dos estados e municípios. A questão que se colocavam os envolvidos na elaboração de um modelo avaliativo naquele momento era se seria possivel adotar uma avaliação em larga escala capaz de oferecer dados mais precisos sobre o rendimento dos alunos. 


\section{Educere Educare \\ ReVISTA DE EduCACÃ̃o}

Programa de Pós-Graduação em Educação - Universidade Estadual do Oeste do Paraná

Esse foi um caminho sem volta, pois o país passou a investir pesado na estruturação de políticas de avaliação que foram ganhando importância na medida em que os sistemas de ensino cresciam e a universalização da educação básica atingia patamares próximos aos $90 \%$ de acesso.

Ainda nos anos 1980, o projeto Edurural, desenvolvido em parceria entre Universidade Federal do Ceará e a Fundação Carlos Chagas, pode ser considerado um marco histórico da definitiva implantação de avaliações externas e em larga escala no Brasil. Envolvendo todos os estados do nordeste

A avaliação acompanhou a implementação e desenvolvimento do projeto, sob vários aspectos, de 1982 a 1986. Avaliaram-se as formas de gerenciamento geral do projeto e, por amostra, o gerenciamento local, analisando-se o sistema de monitoria, os professores, as Organizações Municipais de Ensino (OME), os alunos e as famílias. Desenvolveram-se testes para avaliar crianças em nível de segundas e quartas séries do ensino fundamental, considerando sua pertinência à zona rural em classes, em geral, multisseriadas. Estas provas foram desenvolvidas a partir de amostras de exercícios e trabalhos colhidos nas escolas dos três estados onde a avaliação se desenvolveu - Piauí, Ceará e Pernambuco. Coletaram-se materiais de alunos, trabalhou-se com o pessoal da região e, posteriormente, se deu a forma final das provas. O que se tentava era construir um conjunto de provas tanto quanto possivel adequado àquela realidade, buscando maior validade para os dados de rendimento escolar. As crianças foram avaliadas em 1982, 1984 e 1986. Nesses mesmos anos, os demais dados sobre o programa, seu gerenciamento, as características das escolas, o pessoal docente, as famílias etc., também foram coletados e análises integradas e multivariadas foram feitas procurando encontrar traços característicos relevantes para verificar-se a contribuição socioeducacional do programa, como também os impasses. Análises qualitativas dos dados levantados foram desenvolvidas, tendo sido agregados estudos de caso ao modelo avaliativo, para análise e compreensão em maior profundidade de situações mais específicas (GATTI, 2013, p. 62).

Depois desta experiência, outras sucessivas propostas de avaliação foram realizadas sob comando do Ministério da Educação. Avaliações experimentais em 10 capitais brasileiras envolvendo provas de Língua Portuguesa, Matemática e Ciências foram sucedidas por experiências mais amplas, envolvendo primeiramente 20 capitais brasileiras e, posteriormente, 39 cidades em 14 estados. Essas avaliações, antes realizadas apenas em escolas públicas, passam a ser implementadas em escolas privadas a partir de 1991. Os resultados destas 


\section{Educere Educare \\ ReVISTA DE EDUCACÃ̃o}

Programa de Pós-Graduação em Educação - Universidade Estadual do Oeste do Paraná

avaliações agora em escolas públicas e privadas causou grande repercussão na sociedade, pois apresentou um panorama que supostamente a educação possuía qualidade muito aquém do que se esperava. Isso fez com que o Ministério da Educação adotasse, em 1992, uma política robusta de avaliação. O Sistema de Avaliação da Educação Brasileira (SAEB) institucionalizou por definitivo as avaliações externas e de larga escala no Brasil.

O que ocorreu, em nosso entendimento, foi uma completa inversão de medidas a partir dos diagnósticos evidenciados. Afinal, se o problema já havia sido detectado, baixo aproveitamento da proficiência em determinadas matérias do currículo, por que o foco não passou a ser a melhoria das práticas pedagógicas? Seguindo a tendência global de mensurar a suposta qualidade da educação, o Brasil insere-se na lógica de avaliar com impactos para escolas, professores e alunos, sob a justificativa, como já vimos anteriormente o exemplo dos Estados Unidos, de que estes impactos levariam os envolvidos a melhorar suas práticas. O que se observa, portanto, é a adoção de políticas que não remediam o problema, mas o aprofunda, o torna responsabilidade dos professores e escolas e retira do Estado sua parcela de culpa.

Segundo Bonamino e Souza (2012), o SAEB foi, num primeiro momento, uma avaliação concebida para não apresentar impactos às escolas, mas diagnosticar a qualidade da educação brasileira por meio da seleção de uma amostragem de alunos pertencentes às séries concluintes das etapas da educação básica $\left(5^{\circ}\right.$ ano e $9^{\circ}$ ano do ensino fundamental e $3^{\circ}$ ano do ensino médio). As autoras destacam, entretanto, que a coexistência da avaliação SAEB com as provas realizadas pelos municípios e, mais tarde, a Prova Brasil mudou as características do SAEB tornando-o um sistema avaliativo de impactos para as escolas. As autoras apresentam, ainda, três gerações de avaliações que podem ser compreendidas, também, como três perspectivas de avaliação que o país tem adotado ao longo de sua história: uma primeira geração são as avaliações que não apresentam impactos para as escolas. São de cunho mais diagnósticos e quase sempre difundidos de tal forma que não há 


\section{Educere "Educare \\ ReVISTA DE EduCAČ̃̃o \\ Programa de Pós-Graduação em Educação - Universidade Estadual do Oeste do Paraná}

responsabilização de professores, pais, alunos, gestão das escolas e muito menos premiações ou sansões. A segunda perspectiva ou geração são aquelas que apresentam impactos para as escolas de forma mais moderada. São avaliações de natureza mais diagnósticas, que divulgam publicamente seus resultados, oferecem devolutivas às escolas, mas não há consequências materiais para estas instituições, exceto simbólicas. A terceira geração, a mais usada na história recente da avaliação externa no Brasil, é aquela que prevê sansões materiais para as escolas, oferece premiações e adotam políticas de responsabilização (BONAMINO; SOUZA, 2012).

Como hegemonicamente as avaliações externas, a partir dos anos 1990 e, principalmente, dos anos 2000, preveem políticas de responsabilização, os mais afetados nestas ações são os professores. As consequências das avaliações para estes profissionais são perigosas, pois, ao invés de monitorar o trabalho a fim de aprimorar sua prática, toma o professor como principal responsável pelo sucesso e fracasso da escola nas avaliações. As avaliações em larga escala assumem, portanto, o papel de avaliar/controlar o trabalho do professor, para além de mensurar a aprendizagem dos alunos. Isso vai implicar numa associação, quase direta, entre a qualidade do professor e da aprendizagem para indicar o sucesso ou fracasso da educação de um sistema de ensino.

Essa implicação está intimamente associada à outra tão preocupante quanto à responsabilização dos professores: a associação da qualidade da educação ao desempenho das escolas e seus sistemas de ensino nas avaliações externas. Não há tempo, e também não é foco deste artigo, para discorrer sobre o tema da qualidade da educação e a avaliação em larga escala, mas é preciso destacar que as implicações para educação escolar são importantes na medida em que os conhecimentos deixam de ser trabalhados a partir de sua relevância científica e passam a ser selecionados em razão dos descritores das avaliações. Os professores podem estar selecionando conteúdos não mais a partir de critérios sérios e comprometidos com o desenvolvimento do aluno, mas preocupados em atender aos conteúdos previstos nas avaliações externas. 


\section{Educere Educare \\ ReVISTA DE EduCACÃ̃o}

Programa de Pós-Graduação em Educação - Universidade Estadual do Oeste do Paraná

Em nosso entendimento é preciso retomar o sentido da avaliação e da própria educação escolar, associando ao projeto de sociedade que se pretende formar e destacando o poder da educação para o amplo desenvolvimento humano. Como destacaremos na sequência, a avaliação, quando associada à uma concepção de educação que privilegia o ensino dos conteúdos clássicos, como é o caso da Pedagogia histórico-crítica, avança em direção a refutar a avaliação como ferramenta de punição, responsabilização e destaca sua potencialidade formativa.

\section{PEDAGOGIA HISTÓRICO-CRÍTICA E AVALIAÇÃo}

Quando tratamos do tema da avaliação na educação escolar, logo é possivel pensar nas críticas em torno de processos históricos de ensino, por meio dos quais se impunha um determinado tipo de conhecimento e forma de pensamento que, em linhas gerais, não valorizam a individualidade do ser humano. Entretanto, as críticas que buscam deslegitimar tal modo de ensinar também podem cair na armadilha de negar o próprio conhecimento que se ensina e precisa ser aprendido.

Não é novidade afirmarmos a importância da educação para a constituição do ser humano, seu desenvolvimento para a vida em sociedade, ainda que nos dias atuais esta volte a ser uma defesa necessária na luta cotidiana. A formação humana ao passar pelo processo de educação, pode ganhar novos sentidos e elevar o humano a um nível mais desenvolvido, enriquecendo sua existência e suas relações com os outros indivíduos e com a natureza.

A ação educativa, ao considerar as relações sociais que interferem nela mesma e são modificadas por ela, pode contribuir sobremaneira para que a humanidade se humanize e se transforme conforme suas necessidades reais e emergentes e não, simplesmente, caminhe no compasso do comodismo e da adequação ao que está posto. 


\section{Educere Educare \\ ReVISTA DE EduCAČ̃̃o}

Programa de Pós-Graduação em Educação - Universidade Estadual do Oeste do Paraná

Tais considerações são reforçadas pela defesa do valor e legitimidade da educação para a formação humana:

Se o homem é livre e capaz de intervir na situação, então ele pode intervir na vida das novas gerações para educá-las. [...] A análise do aspecto intelectual, isto é, da consciência, revela que o homem não se mantém preso às suas condições situacionais e pessoais. Ele é capaz de transcender a situação, assim como as opções e pontos de vista pessoais, para se colocar na perspectiva universal, entrando em comunicação com os outros e reconhecendo suas condições situacionais, assim como suas opções e seus próprios pontos de vista (SAVIANI; DUARTE, 2012, p. 14).

Nesta defesa funda-se a definição da educação como uma forma de comunicação entre pessoas de niveis de maturação diferentes, na qual todos os envolvidos se desenvolvem (SAVIANI e DUARTE, 2012). Para tanto, precisamos nos questionar o conteúdo dessa comunicação, o que se comunica e para quê? Tais questionamentos não chegam nem perto de nos satisfazer, mas nos fornecem o pontapé inicial para refletirmos os conhecimentos provenientes das relações que buscam educar o indivíduo, com isso, nos remetem, não muito além, a perguntarmos se efetivamente atingimos nossas expectativas. Assim, dessas dúvidas, retiramos boa parte das nossas ações avaliativas.

Entretanto, precisamos retornar um passo mais atrás de nossas análises para compreendermos o que a avaliação tem como eixo de sua própria investigação: o conhecimento. Na perspectiva histórico-crítica, pautada nos princípios de uma educação emancipatória, estamos nos referindo aos conhecimentos clássicos, imprescindiveis à formação do indivíduo, no sentido da socialização e de sua individualidade.

Não podemos nos enganar e voltar às velhas críticas quanto ao ensino que ganhou status de tradicional, mas, refletir o que a ciência, a arte e a filosofia nos deixam de legado ao longo de nossa própria história. É neste sentido que a pedagogia histórico-crítica, apoiada no materialismo histórico-dialético, ressalta o ensino dos conteúdos clássicos na educação escolar.

Porque clássicos? Clássicos porque não perderam sua relevância para a formação humana, não porque fazem parte de qualquer teoria pedagógica. 


\section{Educere Educare \\ ReVISTA DE EduCAČ̃̃o}

Programa de Pós-Graduação em Educação - Universidade Estadual do Oeste do Paraná

Clássicos porque mantém uma relação intrínseca com a realidade, não porque fazem parte do mundo da fantasia.

Os conhecimentos clássicos permitem ao indivíduo apropriar-se dos produtos do trabalho humano objetivado de tal maneira que possa olhar para a vida cotidiana e compreendê-la em um novo sentido, sob um novo ponto de vista, impingindo-lhe uma nova referência para a ação mais consciente e intencional. Ao passo que esta ressignificação da vida não se restringe à compreensão de fenômenos imediatos ou que fazem parte somente da particularidade do ser, também enriquece sua individualidade.

\footnotetext{
Seja um clássico no campo das artes, ou das ciências, ou da filosofia, o grau de sua eficácia educativa será determinado tanto pela riqueza (pelo valor) de seu conteúdo, em termos de desenvolvimento histórico do gênero humano, quanto pelo significado que esse clássico terá, num determinado momento, para a efetivação das possibilidades de desenvolvimento da individualidade do aluno (DUARTE, 2016, p. 109).
}

$\mathrm{Na}$ dialeticidade entre particular e universal, encontramos a importância do ensino dos conteúdos clássicos na escola desde a educação infantil. Visto que nossa tarefa primordial está em garantir que todas as pessoas tenham acesso ao conhecimento mais desenvolvido.

O ensino e o aprendizado de determinados conhecimentos não subscreve a aceitação ou adaptação do indivíduo a determinadas normas sociais, ou mesmo ao atual modo de organização da sociedade. Ao contrário, partimos da premissa de que precisamos conhecer e nos apropriar dos instrumentos capazes de compreendermos as mais diversas formas pelas quais as relações sociais se constituem e são determinadas. De tal modo que ao nos transformarmos também possamos transformá-las e assim, continuamente construirmos uma sociedade mais humanizada.

Diante desse pensamento, que em nada é romantizado, visto que não desconsideramos as contradições presentes na sociedade e nos conhecimentos que produz, destacamos mais uma vez o papel fundamental da pedagogia, da 


\section{Educere Educare \\ ReVISTA DE EduCACÃ̃o}

Programa de Pós-Graduação em Educação - Universidade Estadual do Oeste do Paraná

escola, do professor e dos sistemas de ensino em garantir uma educação comprometida com a humanização:

O trabalho educativo é o ato de produzir, direta e intencionalmente, em cada indivíduo singular, a humanidade que é produzida histórica e coletivamente pelo conjunto dos homens. Assim, o objeto da educação diz respeito, de um lado, à identificação dos elementos culturais que precisam ser assimilados pelos indivíduos da espécie humana para que eles se formem humanos e, de outro lado e concomitantemente, à descoberta das formas mais adequadas para atingir esse objetivo (SAVIANI, 2005, p. 287).

O que significa que a escola, a priori, tem o dever de conduzir a educação escolar de acordo com as necessidades de formação do gênero humano, pautadas no desenvolvimento do potencial máximo de cada indivíduo. Esta tarefa é primordial ao passo que tais necessidades não são formadas espontaneamente no cotidiano da sociedade capitalista (DUARTE, 2013).

Apesar disso, as políticas de educação e avaliação são hegemonicamente elaboradas para atender as demandas do mercado de trabalho. Não deixam de elencar conceitos científicos, ainda que descartem explicitamente a arte e a filosofia do seu rol de necessidades formativas. Todavia, os conhecimentos científicos presentes na defesa pela aprendizagem ao longo da vida de cada ser humano, estão ancorados no esvaziamento teórico crítico e filosófico, ou seja, não são considerados os conhecimentos que devam instigar a reflexão crítica mais profunda sobre o mundo.

O tipo de educação escolar defendido pelas teorias pedagógicas hegemônicas nas últimas décadas tem limitado o trabalho educativo à satisfação das necessidades cotidianas imediatas e puramente adaptativas. A pedagogia histórico-crítica defende o oposto. Não se trata de uma educação a reboque das necessidades dos alunos, mas de uma produção intencional de necessidades mais ricas, mais complexas e mais elevadas (DUARTE, 2013, p. 215).

A perspectiva de educação e avaliação que apresentamos implica, portanto, o ensino sistematizado de conteúdos escolares que constituem a essência da função social da escola. Superando a aversão social pelo ensino e 


\section{Educere Educare \\ ReVISTA DE EduCACÃ̃o}

Programa de Pós-Graduação em Educação - Universidade Estadual do Oeste do Paraná

aprendizagem de conteúdos determinados pelo currículo e pelo professor, as amarras de conhecimentos acríticos e superficiais fantasiados de "liberdade", o esvaziamento do currículo escolar e a inversão daquilo que deveria ser nuclear com o que é secundário (SAVIANI, 2015).

Os indivíduos não existem isolados, não se formam humanos, no sentido mais pleno de gênero humano, isoladamente ou espontaneamente. Neste processo é primordial a socialização, a vida em sociedade. Com isso, quanto mais ricas as relações sociais, mais rica também poderá se constituir nossa individualidade. "O ser humano só se individualiza e só conquista sua liberdade por meio do desenvolvimento das relações sociais e da realidade humana objetivada. A individualização e a socialização são duas faces de um mesmo processo" (DUARTE, 2013, p. 171). Ou seja, o sentido da individualidade humana se realiza na sua inter-relação com a sociedade.

Podemos nos questionar: O que tem a avaliação com isso? Porque avaliar? Qual o sentido dessa prática diante da perspectiva da avaliação externa?

Temos que considerar a avaliação como parte inerente dos processos de ensino e de aprendizagem. Isso porque a prática de avaliar consiste na possibilidade de intervir conscientemente nas necessidades produzidas pelo ato educativo. O que significa refletir sobre as novas necessidades que podemos e devemos criar no processo de formação humana, mediadas pelos conhecimentos científicos, artísticos e filosóficos presentes na educação do indivíduo.

Tais necessidades são o motor propulsor que justificam os elementos fundantes de uma educação emancipatória, em especial a pedagogia históricocrítica. Pois, nesta direção, possibilitam também a construção do próprio sentido da vida. O que nos remete a considerar a formação da individualidade para si nos processos de avaliação externa, além daquelas propostas pelo próprio professor, no sentido de superarmos um longo processo histórico de negação dessa formação.

Ao pensarmos em uma avaliação que contenha critérios objetivos, com conhecimentos a serem avaliados definidos previamente, não estamos negando a 


\section{Educere Educare \\ ReVISTA DE EduCACÃ̃o}

Programa de Pós-Graduação em Educação - Universidade Estadual do Oeste do Paraná

individualidade do ser como defendem as pedagogias do aprender a aprender. Ao contrário, uma avaliação crítica e emancipatória, que contribua para a apropriação dos conhecimentos mais desenvolvidos pelo ser humano ao longo da história, está, ao mesmo tempo, contribuindo para o desenvolvimento da individualidade para si.

Nossas reflexões nos proporcionaram sintetizar algumas premissas para a elaboração de propostas de avaliação externas que considerem as múltiplas determinações no processo educativo:

1. Avaliação para impulsionar o desenvolvimento do potencial humano em cada indivíduo, consequentemente, impulsionar o desenvolvimento da sociedade.

2. Avaliação que considere a escola, os municípios e estados como expressão da coletividade formada pelas individualidades enriquecidas.

3. A avaliação como elemento que permite a comunicação e entrelaçamento dos objetivos da educação universal, na contramão da alienação e da irreflexão dos aspectos sociais, na direção da construção de um sistema de ensino.

Sendo assim, precisamos intensificar nossa luta também por uma avaliação emancipatória, que, na relação entre os objetivos, os conteúdos escolares, a forma de ensino e a avaliação, se direcione para uma formação omnilateral, com vias ao pleno desenvolvimento do potencial humano no indivíduo.

Ainda que para isso, seja necessário superarmos nossa atual forma de organização social, não podemos negar o máximo que a educação pode oferecer ao ser humano. Neste caso há que se considerar a própria possibilidade da transformação social. 


\section{Educere "Educare \\ REVISTA DE EdUCAC̈̃̃o}

Programa de Pós-Graduação em Educação - Universidade Estadual do Oeste do Paraná

\section{CONSIDERAÇÕES}

A socialização do conhecimento está associada à universalização da riqueza humana no sentido do pleno desenvolvimento do gênero humano em cada indivíduo singular. Entretanto, a universalização do ensino para o sistema capitalista está permeada pelas contradições advindas das defesas do mercado de trabalho, da produção e consumo de mercadorias, das relações desumanizadas. Ou seja, uma universalidade alienada.

Não negamos a necessidade da superação desta sociedade para a efetivação de uma educação, e, consequentemente uma avaliação, que esteja totalmente livre das influências das relações capitalistas. Entretanto, acreditamos ser possivel a construção de uma proposta contra hegemônica, que supere perspectivas reducionistas de ensino e caminhe na direção da conscientização e fortalecimento da luta de classes e da formação da individualidade livre e universal.

Esse é o caráter contraditório da educação escolar.

\section{REFERÊNCIAS}

AMREIN, Audrey; BERLINER, David. High-Stakes Testing, Uncertainty, and Student Learning. Education Policy Analysis Archives, Arizona, USA, v. 10, n. 18, p. 1-74, 2002.

BARONI, Maria Pelissari Monteiro Aguiar; BONFIM, Elias Angelo. A Avaliação da Aprendizagem no Brasil Através dos Documentos Oficiais e a Prática em Sala de Aula: Uma Reflexão Utilizando Como Exemplo a Matemática. POSGERE-PósGraduação em Revista/IFSP-Campus, São Paulo, v. 1, n. 2, p. 5-29, 2017.

BONAMINO, Alícia; SOUZA, Sandra Zákia. Três gerações de avaliação da educação básica no Brasil: interfaces com o currículo da/na escola. Educação e Pesquisa, São Paulo, v. 38, n. 2, p. 373-388, 2012

DUARTE, Newton. A individualidade para si: contribuição a uma teoria histórico-crítica da formação do indivíduo. $3^{\mathrm{a}}$ ed. rev. Campinas, SP: Autores Associados, 2013. 


\section{Educere Educare \\ ReviSTA De EduCAC̄̃̃o}

Programa de Pós-Graduação em Educação - Universidade Estadual do Oeste do Paraná

DUARTE, Newton. Os conteúdos escolares e a ressureição dos mortos: contribuição à teoria histórico-crítica do currículo. Campinas, SP: Autores Associados, 2016.

GATTI, Bernadete. Possibilidades e fundamentos de avaliações em larga escala: primórdios e perspectivas contemporâneas. In: BAUER, A.; GATTI, Bernadete; TAVARES, M., R. Vinte e Cinco Anos de Avaliação de Sistemas Educacionais no Brasil - Origem e Pressupostos. Florianópolis: Insular, 2013. p. 47-69. (Ciclo de Debates, v. 1)

. Testes e avaliações do ensino no Brasil. Educação e Seleção. São Paulo, v. 16, pp. 32-42, 1987.

SAVIANI, Dermeval e DUARTE, Newton. A formação humana na perspectiva histórico-ontológica. In: SAVIANI, Dermeval e DUARTE, Newton (orgs.).

Pedagogia histórico-crítica e luta de classes na educação escolar. Campinas, SP: Autores associados, 2012, p. 13-35.

SAVIANI, Dermeval. Sobre a natureza e especificidade da educação. Germinal: Marxismo e Educação em Debate, Salvador, v. 7, n. 1, p. 286-293, jun. 2015.

Recebido em: 19-03-2020 Aceito em: 16-04-2020 